Original Article

\title{
PRELIMINARY PHYTOCHEMICAL SCREENING AND IN VITRO ANTI-MICROBIAL ACTIVITY OF ETHANOLIC EXTRACT OF STEMS OF THE PLANT TAGETES ERECTA L. (FAMILY-ASTERACEAE)
}

\author{
JAFAR ALI*, DIBYENDU SHIL
}

Girijananda Chowdhury Institute of Pharmaceutical Science Azara, Guwahati, India

Email: j1f1r14@gmail.com

Received: 22 Apr 2018, Revised and Accepted: 10 Jun 2018

\begin{abstract}
Objective: To estimate the anti-microbial activity of ethanolic extract of Tagetes erecta L. (family-Asteraceae) in association with phytochemical analysis.

Methods: The ethanolic extract of the stems of TageteseErecta L. was prepared and investigate for phytochemical constituents using standard methods. Antimicrobial activity of ethanolic extract of has been carried out against one Gram positive bacteria-Staphylococcus aureus and one Gram negative bacteria-Escherichia coli, and the antifungal activity of the plant extract was evaluated on Candida albicans species. The testing was done by the disc diffusion method to visualize the zone of inhibition of ethanolic extract was compared with that of standard drug i.e., Ciprofloxacin for antibacterial activity and Terbinafine for anti-fungal activity. The MIC was determined by the microdilution method (Cup-plate method).
\end{abstract}

Results: The present investigation shows the phytochemical analysis, antimicrobial activity of the ethanolic extract of the stems of Tagetes erecta L. Various phytochemical analysis confirmed the presence of alkaloids, saponin glycosides, flavonoids, phenol, proteins and amino acids, cardiac glycosides, steroids, tanin and phenolic compounds. The anti-microbial activity of the ethanolic extract of the plant showed significant results against all three of the test organisms in compare to the standard drugs.

Conclusion: The present study concluded that ethanolic extract of-of the stems of Tagetes erecta L. Proved the existence of phytochemical constituents. The ethanolic extract of the plant was found to possess promising antimicrobial activity when compared with the standards and it can be useful for the development of the antibiotics.

Keywords: Tagetes erecta, Anti-microbial, Agar disc diffusion method, Zone of Inhibition, Minimum Inhibitory Concentration, Phytochemical screening (C) 2018 The Authors. Published by Innovare Academic Sciences Pvt Ltd. This is an open access article under the CC BY license (http://creativecommons.org/licenses/by/4.0/) DOI: http://dx.doi.org/10.22159/ijcpr.2018v10i4.28468

\section{INTRODUCTION}

HERBAL MEDICINE: By definition, 'traditional' use of herbal medicines implies substantial historical use, and this is certainly true for many products that are available as 'traditional herbal medicines'. In many developing countries, a large proportion of the population relies on traditional practitioners and their armamentarium of medicinal plants in order to meet health care needs. Although modern medicine may exist side-by-side with such traditional practice, herbal medicines have often maintained their popularity for historical and cultural reasons. Such products have become more widely available commercially, especially in developed countries. In this modern setting, ingredients are sometimes marketed for uses that were never contemplated in the traditional healing systems from which they emerged. An example is a use of ephedra (Ma huang) for weight loss or athletic performance enhancement. While in some countries, herbal medicines are subject to rigorous manufacturing standards, this is not so everywhere. In Germany, for example, where herbal products are sold as 'phytomedicines', they are subject to the same criteria for efficacy, safety and quality as are other drug products [1].

According to the World Health Organization (WHO), the use of herbal remedies throughout the world exceeds that of the conventional drugs by two to three times. In the last few decades, there has been an exponential growth in the field of herbal medicine. It is getting popularized in developing and developed countries owing to its natural origin and lesser side effects. Nature has provided a complete storehouse of remedies to cure all ailments of mankind. About $80 \%$ of the world population depending on the herbal-based alternative system of medicine like Ayurveda. Herbal drugs have played a vital role in curing diseases throughout the history of mankind. Despite the major advances in the modern medicine, the development of new drugs from natural products is still considered important. An estimated 70,000 plants are used medicinally. Ayurveda utilizes about 2000 plants to cure different ailments. There are very few medicinal herbs of commercial importance, which are not cultivated in our country. Approximately 1250 Indian medicinal plants are used in formulating therapeutic preparations, according to Ayurveda and other traditional systems of medicine. The evaluation of various plant products according to their traditional uses and medicinal value based on their therapeutic efficacy leads to the discovery of newer and recent drugs for treating various ailments [2].

Antibiotic resistance is a growing problem. The wide spirit and indiscriminate uses of antibacterial agents resulted in the development of resistance among many virulently pathogenic bacteria species. Many of the currently used antibacterials are associated with adverse effects such as toxicity, hypersensitivity, immune suppression, and tissue residues posing a public health hazard. Alternative System of Medicine viz. Ayurveda, Siddha, and Traditional Chinese Medicine have become more popular in recent years. According to one estimate, more than 700mono and polyherbal preparations in the form of decoction, tincture, tablets and capsules from more than 100 plants are in clinical use. Tagetes erecta L. family-Asteraceae, commonly known as Pot Marigold is an important medicinal plant used in our Traditional System of Medicine to treat various diseases. Tagetes erecta L. is widely cultivated and can be grown easily in sunny locations in most kinds of soils. It is commonly treated as an annual, particularly in colder regions where its winter survival is poor and in hot summer locations where it also does not survive. In areas of limited winter freezing, seeds are sown in autumn. Seeds will germinate freely in sunny or half-sunny locations, but plants do best if planted in sunny locations with rich, well-drained soil [3].

Antibiotics play a vital role in dental practice for managing orofacial infections. They are used to manage existing infection 
and they are also used as prophylaxis for certain medical conditions and surgical procedures. Antibiotics are generally classified according to their molecular structure and their antimicrobial mechanisms. Ideally, these mechanisms of action either interrupt synthesis of structural components or alter specific metabolic functions that are unique to microbial cells. The effectiveness of a particular antibiotic for managing specific infections is predicated on 3 variables: (a) the antibiotic's minimum inhibitory concentration (MIC)-90 for the pathogen, (b) its peak serum level, and (c) its elimination half-life.

a. The MIC-90 represents the serum concentration required to inhibit or destroy $90 \%$ of the species for a selected class of microorganisms. It is important to consider that an antibiotic may exhibit activity in vitro, but it is of little use if this concentration cannot be achieved in the tissue infected.

b. Following PO administration, serum concentration must exceed the MIC-90.

c. An antibiotic is ineffective if its elimination pattern does not sustain an acceptable serum concentration for a reasonable period of time. Concentration drops by $50 \%$ each half-life [4].

\section{MATERIALS AND METHODS}

\section{Collection of plant materials}

Tagetes erecta was collected from Cherekapar, Sivasasgar, Assam in January 2018. The plant is authenticated by Dr. P. P Baruah, Head of dept. of Botany, Guwahati University. A voucher specimen for Tagetes erecta has been stored in the form of herbarium (Acc. No 18390 dt: 27/01/2018) was kept in dept. of Botany, Guwahati University for further reference.

\section{Chemicals and reagents}

Petroleum Ether (PE), Ethanol (ET), Chloroform, Dimethyl Sulfoxide (DMSO), Hydrochloric acid ( $\mathrm{HCl})$, Dragondorff's reagent, Mayer's reagent, Wagner's reagent, Benedict's reagent, Sulfuric acid $\left(\mathrm{H}_{2} \mathrm{SO}_{4}\right)$, lead acetate, Molisch's reagent, Fehling solution A and B, copper sulphate, 5\% Ferric chloride, Sodium hydroxide $(\mathrm{NaOH})$, glacial acetic acid, benzene, chloroform, ammonia, nitric acid $\left(\mathrm{HNO}_{3}\right), 95 \%$ Ethanol, Beef extract, Peptone and agar. All the chemicals and solvents used were of standard analytical grades.

\section{Preparation of extract}

The whole plant was collected, separate the leaf and flower petals, etc from it and the remaining stems is washed under running tap water to remove dust particles, dirt and foreign particles, shade dried and then kept at tray drier at $37^{\circ} \mathrm{C}$ for 48 h. Using a manual grinder to grind or crush it into a sort of powder. Then firstly it was extracted with Petroleum Ether by using soxhlet apparatus (Borosil, India) to defatted the fatty layer from it and then extracted with chloroform, ethanol successively in order of their increasing polarity by maceration process until it got to be distinctly dry as indicated by the standard techniques (steam distillation was performed). The solution was filtered using Whatman no. 4 filter paper and the filtrate was concentrated to a semi-solid residue in a rotary vacuum evaporator and kept in the desicator for further anti-microbial analysis [5]

The extract acquired was weighed and the rate yield was figured as far as the dried weight of the plant material utilizing the equation:

Calculation of percentage yield $=$ (Dry weight of the extract/Dry weight of sample) x100.

\section{Phytochemical screening}

Firstly, the plant extract was prepared as a test solution in a test tube, and was then tested for the presence of alkaloids, saponin glycosides, flavonoids, phenol, carbohydrates, reducing sugars, monosaccharides, proteins and amino acids, cardiac glycosides, steroids, tanin and phenolic compounds using the standard procedure $[6,7]$.

\section{Bacterial strains}

The two bacterial strains [Staphyllococcus aureus (ATCC 25923), Escherichia coli (ATCC 25922)] were used. Stains were obtained from Girijananda Chowdhury Institute of Pharmaceutical Science, Azara, Guwahati.

\section{Antibacterial and antifungal assay}

The antimicrobial action of the plant extract was measured by agar well diffusion technique as described in NCCLS, 1993 [8]. Petri plates containing $20 \mathrm{ml}$ nutrient agar medium was prepared with bacterial strains separately. Plant extract was prepared in DMSO $(1 \mathrm{mg} / \mathrm{ml}$ DMSO) using serial dilution method by taking the extractive yield of the ethanolic extract. The proper shaped of the small disc of Whatman filter paper was made and put a drop of the extracts on it and placed on the microbes containing petri plates on it. The plates were then incubated at $37^{\circ} \mathrm{C}$ for 24 hour. The diameter of the zone of inhibitions was measured in "mm" after $24 \mathrm{hr}$. All the procedure was performed under sterile conditions. Ciprofloxacin and Terbinafine served as positive controls $[9,10]$.

\section{Minimum inhibitory concentration}

The Minimum Inhibitory Concentration (MIC) of ethanolic extract was determined as the lowest concentration of the plant extract inhibiting the visible growth of the organism [11].

It involves the following steps-

- A stock solution of the plant extracts was prepared by taking a concentration of $1 \mathrm{mg} / \mathrm{ml}$ (stock solution)

- A new concentration is obtained by diluting the extract with the solvent $10 \mu \mathrm{g} / \mathrm{ml}, 20 \mu \mathrm{g} / \mathrm{ml}, 30 \mu \mathrm{g} / \mathrm{ml}$ and up to $100 \mu \mathrm{g} / \mathrm{ml}$ respectively (test solution)

- The concentration necessary to cause minimum inhibition was then determined by the cup-plate method.

\section{RESULTS}

The present study shows the phytochemical screening, anti-microbial activity of the ethanolic extract of the plant Tagetes erecta and the percentage yield of the extraction of the ethanol was found to be $3.45 \%$.

\section{Phytochemical screening}

The qualitative phytochemical screening of plant extract confirmed the presence of various chemical constituents like alkaloids, saponin glycosides, flavonoids, phenol, proteins and amino acids, cardiac glycosides, steroids, tannins and phenolic compounds.

\section{Antibacterial activity}

The plant extract are rich in antibacterial components. The in vitro antibacterial activity of the ethanolic extract of Tagetes erecta is determined by the agar disc-diffusion method.

\section{Antifungal activity}

The extract was carried out for antifungal activity with respect to the provided standard drug.

Table 1: Antibacterial activity of stems of ethanolic extract of Tagetes erecta observed against the growth of bacteria using disc diffusion method

\begin{tabular}{lll}
\hline Compounds & Inhibition zone S. aureus (mm) & Inhibition zone E. coli (mm) \\
\hline $\mathrm{A}(1)$ & 26.39 & 24.22 \\
$\mathrm{~B}(2)$ & 17.19 & 15.28 \\
\hline
\end{tabular}

Where, $\mathrm{A}=$ Ciprofloxacin $(30 \mu \mathrm{l}), \mathrm{B}=$ plant extract $(100 \mu \mathrm{l})$ 


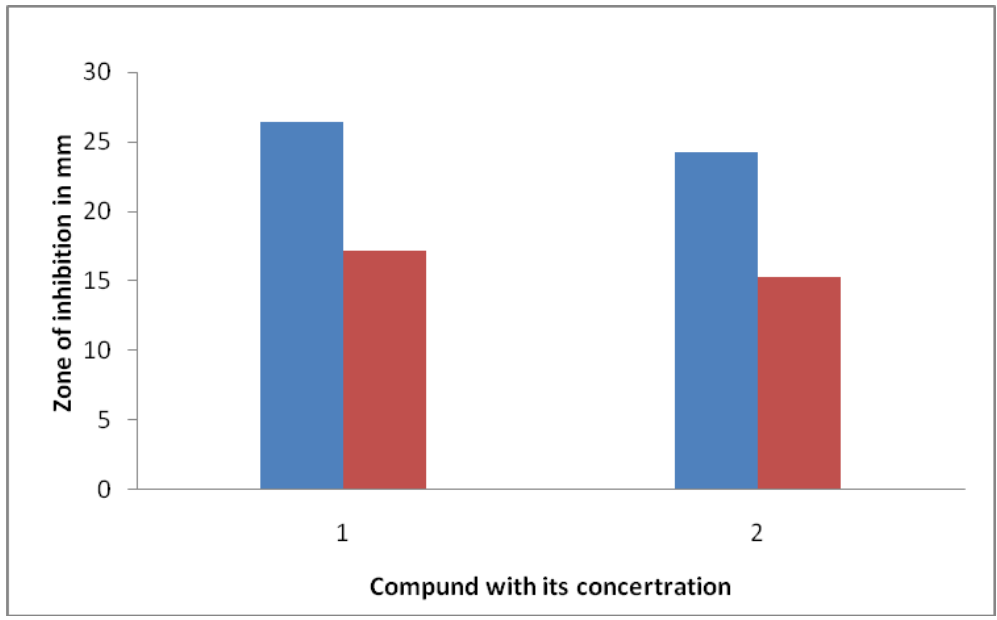

Fig. 1: Zone of inhibition vs concentration

Table 2: Antifungal activity of stems of ethanolic extract of Tagetes erecta observed against the growth of fungi using disc diffusion method

\begin{tabular}{ll}
\hline Compounds & Inhibition zone candida albicans (mm) \\
\hline $\mathrm{A}(1)$ & 21.77 \\
$\mathrm{~B}(2)$ & 13.58 \\
\hline
\end{tabular}

Where, $\mathrm{A}=$ Terbinafine, $\mathrm{B}=$ Plant extract

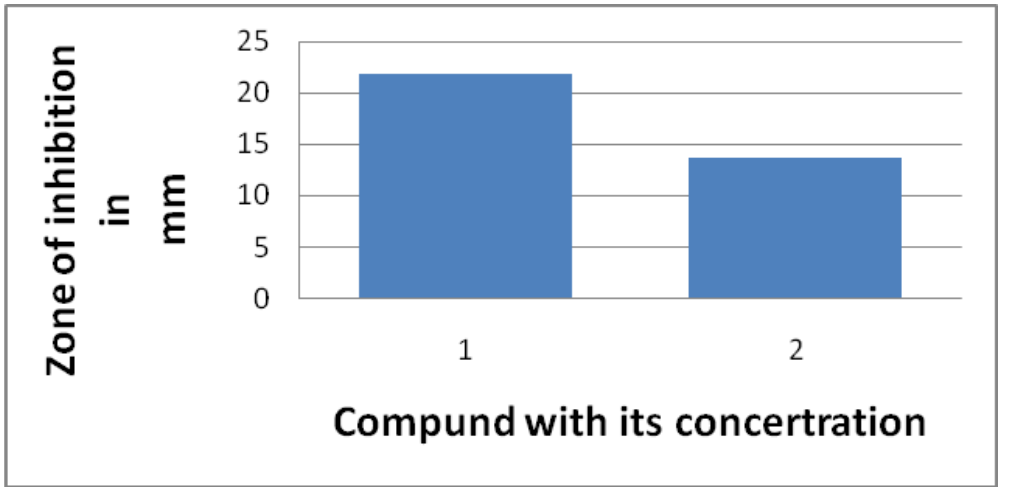

Fig. 2: Zone of inhibition vs concentration

\section{Minimum inhibitory concentration}

1. For gram positive bacteria (S. aureus): The MIC of the extract was found to be $120 \mu \mathrm{g} / \mathrm{ml}$.

2. For gram negative bacteria (E. coli): The MIC of the extract was found to be $250 \mu \mathrm{g} / \mathrm{ml}$.

3. For fungi (Candida abicans): The MIC was found to be $500 \mu \mathrm{g} / \mathrm{ml}$.

\section{CONCLUSION}

The result confirms that it has the significant antimicrobial activity of the extract Tagetes erecta L. The plant extracts have great potential as antimicrobial compound against disease-causing microorganisms. No doubt, the pathogens can develop resistance against the antibiotic if the same is used for longer periods of time and also if not necessary. The antibiotic is gradually unable to resist the growth of the pathogens.

This study includes the anti-microbial activity of the stems of Tagetes erecta $\mathrm{L}$. was evaluated by using the agar disk diffusion method. The microorganisms select to be studied were Gram positive i.e., Staphyllococcus aureus and Gram negative i.e.,
Escherichia coli and fungi is Candida albicans. However, it always be in mind to prevent from resistant against microorganism while discovering new drugs, meanwhile, it has been anticipated that this study would guide to the creation of some new compounds that can be used to develop new and more powerful anti-microbial drugs.

\section{ACKNOWLEDGEMENT}

The author is highly grateful to Mr Dibyendu Shil, Assistant Professor, HOD Department of Pharmacognosy, Girijananda Chowdhury Institute of Pharmaceutical Science, Azara, Guwahati, India for his valuable support and guidance provided during this work and Head of the Department, Guwahati university for authentication of the plant specimen and Department of Microbiology, Girijananda Chowdhury Institute of Pharmaceutical Science, Azara, Guwahati for conveying this experimental work to discover the very importance values of the same.

\section{AUTHORS CONTRIBUTIONS}

All the author have contributed equally

\section{CONFLICT OF INTERESTS}

Declared none 


\section{REFERENCES}

1. Awang DVC. Quality control and good manufacturing practices: safety and efficacy of commercial herbals. Food Drug Law Inst 1997;52:341-4.

2. Brahma Chari UN. Herbal remedy. Curr Sci 2001;81:15-6.

3. Zitterl Eglseer K, Sosa S, Jurenitsch J, Tubaro A, Franz C. Antiedematous activities of the main triterpendiol esters of marigold. J Ethnopharmacol 1997;57:139-44.

4. Kuriyama T, Karasawa T, Nakagawa K, Saiki Y, Yamamoto E, Nakamura S. Bacteriologic features and antimicrobial susceptibility in isolates from orofacial odontogenic infections. Oral Surg Oral Med Oral Pathol Oral Radiol Endod. 2000;90:600-8.

5. Kurian S, Josekumar VS. Phytochemical screening, antimicrobial activity and brine shrimp lethality bioassay of different extracts of Alysicarpus vaginalis var. nummularifolius (DC.) MIQ. (family: fabaceae). Int J Pharm Sci 2017;9:1-6.

6. Tiwari P, Kumar B, Kaur M, Kaur G, Kaur H. Phytochemical screening and extraction: a review. Int Pharm Sci 2011;1:98-106.
7. Ibironke AA, Sarah ON, Adewale A. Anti-microbial activity and phytochemical screening of five selected seeds from Nigeria. Int J Biomed Pharm Sci 2010;4:104-6.

8. National Committee for Clinical Laboratory Standards. Performance Standards for Antimicrobial Disk Susceptibility Tests. Fifth Edition: Approved Standard M2-A5. NCCLS, Villanova, PA; 1993a.

9. Tankeshwar Acharya. "Nutrient agar: composition, preparation and uses." Microbes online. Available from: https:// microbeonline.com [Last accessed on 10 Apr 2018]

10. Chetan PS, Murugananthan G, Komaleeswari K. Evaluation of antimicrobial activity of methanolic extract fractions of Delonix elata bark. Int J Res Ayurveda Pharm 2012;3:425-7.

11. Tankeshwar Acharya. Minimum inhibitory concentration (MIC): Broth dilution method-procedure and interpretation."Microbes online. Available from: https://microbeonline.com. [Last accessed on 10 Apr 2018] 